\title{
Consumer awareness of food antioxidants. Synthetic vs. Natural
}

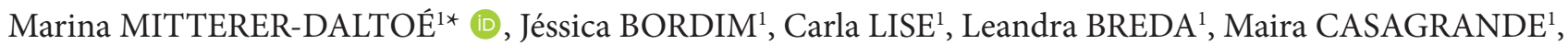 \\ Vanderlei LIMA ${ }^{1}$
}

\begin{abstract}
Food antioxidants are a core topic of food science due mainly to the consumption of ultra-processed foods, which cannot be overlooked, and represent an importance to modern society. At the same time, natural food antioxidants are gaining attention in studies due to its food safety aspects, that commonly affect food choices. Based on this, the present study aimed to explore the cognitive evaluation of food antioxidants by consumers using the qualitative consumer technique Word Association. Two stimuli were given. Respondents were first asked to write down the first four words that came to mind; descriptions, associated thoughts, or feelings when reading "Food Antioxidants". Secondly the word Natural was added and the stimulus was "Natural Food Antioxidants". The Word Association technique has been shown to be an important tool for cognitive evaluation of the perception of food antioxidants, and the dimensions, Health, Food Safety, Preservatives, Source and Preference which arose and differentiated the stimuli. The results revealed some prior knowledge about issues related to food antioxidants, natural or not. Additionally, showed a clear potential use for natural food antioxidants by the food industry, judging by consumer perception that primarily related cognitively to positive aspects of healthy and food safety.
\end{abstract}

Keywords: food safety; natural sources; perception; health; preservatives; Word Association.

Practical Application: To increase natural antioxidant use by the food industry, consumers' knowledge and perception emerge as important tools.

\section{Introduction}

Food antioxidants are a core topic of food science Cömert \& Gökmen (2018). This strong claim is due mainly to the consumption of ultra-processed foods, which cannot be overlooked, since they are characterized by convenience as well as long shelf life (Ribeiro et al., 2019), which represent a demand of modern society (Shim et al., 2011).

This long shelf life for a wide range of products is achieved by adding antioxidants to prevent the rancidity caused by oxidation of unsaturated fats and to conserve the nutritive value of food by preventing carotenes and various fat soluble vitamins from oxidation (Cömert \& Gökmen, 2018). Additionally, antioxidants are not just used as a food preservative, but also as compounds that have an important effect on the biochemistry of the human organism, suppressing oxidation processes and preventing chronic diseases related to oxidative stress (Cömert \& Gökmen, 2018). Thus, in this scenario, natural antioxidants have been gaining great attention in several studies in recent years, as an important healthy alternative to replace synthetic antioxidants that have been identified as toxicological and carcinogenic agents in some studies (Kumar et al., 2015).

The importance given by consumers to food safety issues (Lagerkvist et al., 2018; Wongprawmas \& Canavari, 2017) and healthy eating (Carrillo et al., 2011; Rembischevski \& Caldas, 2020) can determine the potential future of any food ingredient (Varela \& Fiszman, 2013). As mentioned by Grunert (2005) quality and safety perception by consumers is greatly related to food choice, consumer demand and can be connected to price perception and willingness to pay (Gifford \& Bernard, 2011).

Studies have analysed responses toward food safety issues (Latorres et al., 2016; Miles et al., 2004; Ruby et al., 2019), toward chemicals in foods (Dickson-Spillmann et al., 2011) and food ingredients or additives (Aoki et al., 2010; Shim et al., 2011; Varela \& Fiszman, 2013).

Important common conclusions were noted among studies: Consumers demonstrate little knowledge about additives (Varela \& Fiszman, 2013) but are conscious of their lack of information, making it difficult to understand the subject of food additives (Aoki et al., 2010; Shim et al., 2011). It could also be shown that consumers are very concerned about additives (Shim et al., 2011; Varela \& Fiszman, 2013) and chemicals in their diet (Dickson-Spillmann et al., 2011) and that food safety perception of additives is affected by consumer awareness and knowledge (Aoki et al., 2010; Shim et al., 2011).

Additional important conclusions to be highlighted are the positive prospects for additives/ingredients with natural origins (Varela \& Fiszman, 2013), since risk awareness of chemicals in food are positively correlated with a preference for natural additives, and are perceived differently according to their origin (synthetic vs natural) (Dickson-Spillmann et al., 2011).

${ }^{1}$ Programa de Pós-graduação em Tecnologia de Processos Químicos e Bioquímicos, Departamento de Química, Universidade Tecnológica Federal do Paraná - UTFPR, Pato Branco, PR, Brasil

${ }^{*}$ Corresponding author: marinadaltoe@utfpr.edu.br 
What has happened so far is that although successful results have been reported, the studies that have analyzed responses toward food additives or ingredients have always been for additives in general and not specifically for antioxidants. As a first research with a focus on antioxidants, the aim of the present study is to explore the cognitive evaluation of food antioxidants by consumers using the qualitative consumer technique Word Association.

\section{Materials and methods}

\subsection{Consumers}

A total of 96 consumers ( 52 female and 44 male) were included in the study. The participants were from southwestern Paraná, Brazil and aged between 20 and 60 years old. The consumers were recruited via e-mail from a database.

\subsection{Word Association task}

Word Association was applied according to Ares et al. (2008) and Latorres et al. (2016). The same two stimuli were given to all participants. The first instruction was: "Write down the first four words, descriptions, associated thoughts or feelings that came to your mind when you read Food Antioxidants". For the second, the word Natural was added and the stimulus became "Natural Food Antioxidant". The second instruction was: "Write down the first four words, descriptions, association thoughts or feelings that came to your mind when you read Natural Food Antioxidants".

\subsection{Data analysis}

Data analysis was based on Antmann et al. (2011). All associations were included. Associations were grouped into different categories, which were then grouped into different dimensions. The grouping was done independently by five researchers.

After evaluating the data individually, researchers met to confirm the similarities in their classifications. The final categories and their names were determined by consensus between the researchers. Categories mentioned by more $5 \%$ of the participants were included in the analysis. The dimensions and categories between stimuli were submitted to the z-test, a significance test that allows accepting or rejecting hypotheses (Latorres et al., 2016; Mazon et al., 2020).

To better understand and visualize the categories that represent each stimulus, word clouds maps were applied. The word clouds were performed using the Orange 3.23 software.

\section{Results and discussion}

\subsection{Cognitive evaluation of food antioxidants}

Word Association technique is supported by the hypothesis that when the participant is given a stimulus and asked to freely associate it with what comes to his mind, we obtain unrestricted access to the mental representations that the stimuli provide. The first associations that come to the minds of the participants are considered the most relevant (Latorres et al., 2016; Roininen et al., 2006; Varela \& Fiszman, 2013).
Table 1 shows the dimensions and categories obtained from the results of the word association task. Seven dimensions were built by consensus among the five researchers who took part in analyzing the data. Words with similar meanings were grouped in the same category. The dimensions which appeared, based on stimuli were: Health, Preservatives, Sensory attributes, Food Safety, Source and Preference.

What can be seen is that "Food Antioxidant" or "Natural Food Antioxidant" are stimuli that are clearly related to health issues by consumers, judging by the number of categories that compound the dimension Health and the frequency of mentions for each category.

The negative health perception for the stimulus "Food Antioxidant" is clearly seen by the category harmful to health that was cited by $39.6 \%$ of the participants. When the word Natural was added, the perception was targeted for a positive health perception as seen by the categories Healthy and Well-being. In other words, food antioxidant additives are seen as unhealthy and natural food antioxidant additives as healthier. According to Carrillo et al. (2011) and Clarke \& Best (2017) positive health benefit perception is important to the food industry since the health perception of a determined food has a positive influence on buying behavior. Therefore, from this point of view the results should encourage food industries to use natural food antioxidants.

Table 1. Frequency of dimensions and categories for the stimuli: "Food antioxidants" and "Natural Food Antioxidants".

\begin{tabular}{|c|c|c|c|}
\hline $\begin{array}{c}\text { Dimensions and } \\
\text { categories }\end{array}$ & $\begin{array}{c}\text { Food } \\
\text { Antioxidants }\end{array}$ & $\begin{array}{l}\text { Natural Food } \\
\text { Antioxidants }\end{array}$ & z-test \\
\hline HEALTH & 71 & 86 & 2.803876 \\
\hline Harmful to health & 38 & 0 & 6.883068 \\
\hline Anti-Aiging & 9 & 10 & 0.24169 \\
\hline Healthy & 18 & 56 & 5.63478 \\
\hline Well-being & 2 & 11 & 2.5852 \\
\hline Diseases Prevention & 4 & 9 & 1.43622 \\
\hline PRESERVATIVES & 70 & 28 & 6.063499 \\
\hline Rancidity & 10 & 0 & 3.247992 \\
\hline Free radicals & 6 & 5 & 0.310538 \\
\hline Stability & 14 & 13 & 0.2076 \\
\hline Preservation & 29 & 10 & 3.408209 \\
\hline Shelf Life & 11 & 0 & 3.41592 \\
\hline SENSORY ATTRIBUTES & 8 & 6 & 0.555138 \\
\hline Flavor & 8 & 6 & 0.555145 \\
\hline FOOD SAFETY & 46 & 49 & 0.433036 \\
\hline Food Safety & 7 & 18 & 2.35893 \\
\hline Reliability & 0 & 10 & 3.24799 \\
\hline Distrust & 21 & 14 & 1.308473 \\
\hline Unknown & 7 & 7 & 0 \\
\hline Lack of confidence & 11 & 0 & 3.41592 \\
\hline SOURCE & 43 & 53 & 1.443366 \\
\hline Fruits & 4 & 14 & 2.47594 \\
\hline Plants & 2 & 12 & 2.77573 \\
\hline Natural & 2 & 27 & 5.03846 \\
\hline Synthetic & 35 & 0 & 6.542366 \\
\hline PREFERENCE & $\mathbf{0}$ & 12 & 3.577731 \\
\hline Better & 0 & 12 & 3.57771 \\
\hline
\end{tabular}


Another dimension that can be related to health perception is Food Safety. This dimension also corroborates the healthier perception given by the stimulus "Natural Food Antioxidant" evaluated by the differences found between stimuli in the categories: Food Safety, Reliability and Lack of confidence. These categories made clear that for consumers, food antioxidants are not perceived as reliable and safe, and when the word natural was added a better perception was noted.

The relationship between food safety and reliability was previously recorded in literature (De Jonge et al., 2008; Lagerkvist et al., 2018; Latorres et al., 2016). Studies also indicate that food safety has an impact on consumers' willingness to pay (Riccioli et al., 2020), pointing out that consumers assign a higher value for safer food (Wongprawmas \& Canavari, 2017).

This willingness to pay for a safer food also suggests a good potential food market for the use of natural food antioxidants based on the optimistic categories related to this stimulus, Food safety and Reliability.

The optimistic categories indicate the extent to which consumers are satisfied about the safety of food, it is worth noting that the category Distrust appeared for both stimuli without differences. This behavior is in accordance with De Jonge et al. (2008). The authors highlight that the concept of consumer reliability in food safety is bidimensional and that the feeling of optimism and pessimism can co-exist, but that these should be considered distinct but always dependent and related concepts. Therefore, the categories Food safety, Reliability, Distrust, Unknown and Lack of confidence obtained by the word association technique can individually represent each stimulus about food safety issues, but the relation among categories cannot be overlooked.

The dimension Source also offered an interesting approach to the stimuli which again relates to health and food safety concerns. The rise of the Natural and Synthetic categories clearly represents the consumers perception about the source of each stimulus. When the stimulus "Food Antioxidant" was given, the participants linked to a synthetic source of this food ingredient. When the word Natural was added to the stimulus the category Natural experienced a sharp rise. For consumers, natural sources of the "Natural Food Antioxidants" are represented mainly by fruits and plants.

The differences expressed at the mention of Synthetic and Natural sources between stimuli represent good news for the potential use of natural food antioxidants by the industry. According to Dickson-Spillmann et al. (2011) consumers express concerns about chemicals in their diet, and perceive additives differently according to their origin. The authors also highlighted that the perception of risk of chemicals in food were positively correlated with a preference for natural food.

Preservatives were another dimension that emerged from the given stimuli. This dimension was generated by the categories Rancidity, Free radical, Stability, Preservation and Shelf life, which reveal that consumers know what it is for, and are aware of the application of antioxidants in foods. This knowledge was significantly better when related to the first stimulus, with 70 mentions.
When the second stimulus was given and the word natural was added what can be verified is that this dimension was no longer among the main perceptions among consumers. However, it is noteworthy that this behavior does not indicate that participants do not think that conservation is not a function of the natural antioxidant. What happens is that associations change the main focus.

Until now, discussions of the results show that natural food antioxidants are well perceived by consumers and have good potential for the market and/or food industry. Additionally, the cognitive evaluation of food antioxidants by the word association technique also clearly showed a preference between stimuli. The dimension Preference generated by the category Better appeared 12 times when the second stimulus with the word Natural was given, corroborating the evaluation of the previous dimensions.

To better understand this preference and the categories that represent each stimulus, a word clouds map was applied (Figures 1 and 2). Word clouds are graphical maps that shows words in proportion depending on their frequency of use (Frunzeanu, 2015; Jin, 2017). The graphical maps show the most cited categories for both stimuli. As the size of font represents the number of mentions by consumers, a pattern can clearly be seen: the stimulus "Food Antioxidant" is directly related to a concern about harm to health and synthetic sources. In the

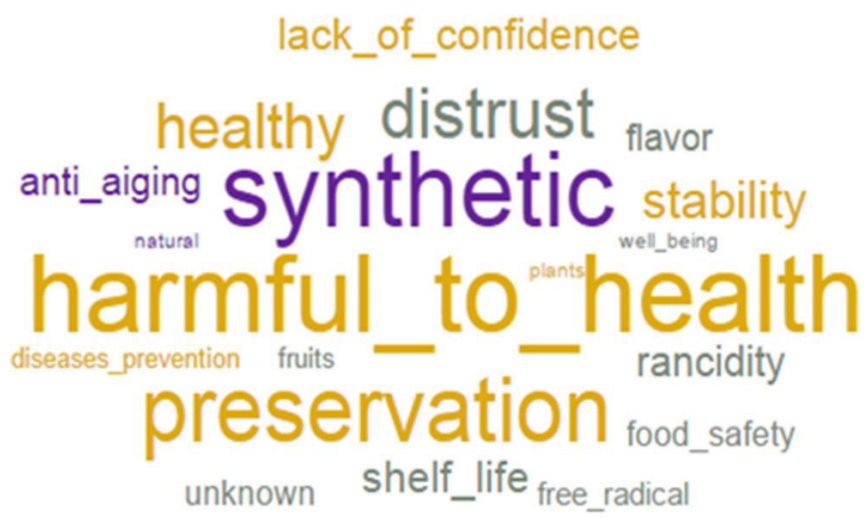

Figure 1. Word cloud from the categories that appeared from the stimulus "Food Antioxidants".

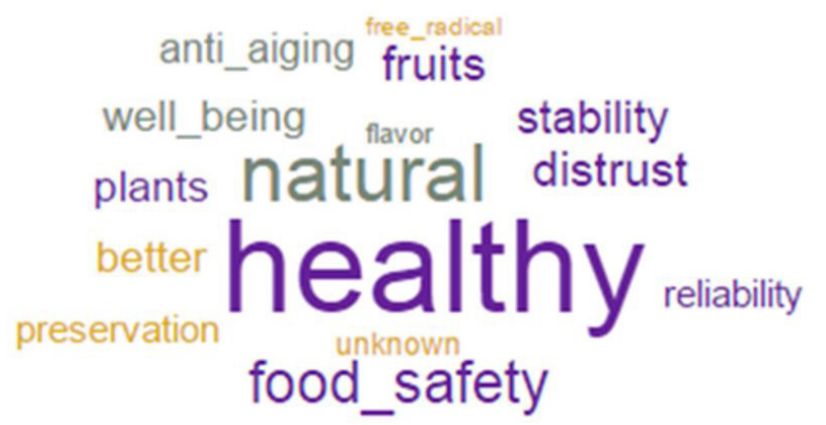

diseases_prevention

Figure 2. Word cloud from the categories that appeared from the stimulus "Natural Food Antioxidants". 
meantime, consumers are also aware that food antioxidants have preservative functions. On the other hand, the stimulus "Natural Food Antioxidant" is directly related to a health and food safety perception, probably resulting from the natural source.

\section{Conclusions}

The Word Association method has been shown to be an important tool for cognitive evaluation of the perception of food antioxidants. For the present study the results indicate a clear difference in perception between stimuli given. Health, Food Safety, Preservatives, Source and Preference were the dimensions that arose and differentiated the stimuli.

The results revealed some prior knowledge about issues related to food antioxidants, natural or not, and arose as a starting point to explore more feedback from consumers. Future studies need to explore consumer knowledge, resulting actions and demographic traits on the subject of food antioxidants, since it is known that these topics determine the commercial future of any food ingredient. The previous study showed a clear potential use of natural food antioxidants by the food industry, judging by consumer perception that cognitively related the positive aspects of health and food safety.

\section{Ackowledgements}

The authors thank The Federal University of Technology - Pato Branco (UTFPR) and CAPES Foundation, the Ministry of Education of Brazil and acknowledge the technical support provided. Thanks also to Robert Lee for his assistance with the English manuscript.

\section{References}

Antmann, G., Ares, G., Salvador, A., Varela, P., \& Fiszman, S. (2011). Exploring and explaining creaminess perception: consumers' underlying concepts. Journal of Sensory Studies, 26(1), 40-47. http:// dx.doi.org/10.1111/j.1745-459X.2010.00319.x.

Aoki, K., Shen, J., \& Saijo, T. (2010). Consumer reaction to information on food additives: evidence from an eating experiment and a field survey. Journal of Economic Behavior \& Organization, 73(3), 433438. http://dx.doi.org/10.1016/j.jebo.2009.11.007.

Ares, G., Giménez, A., \& Gámbaro, A. (2008). Understanding consumers ' perception of conventional and functional yogurts using word association and hard laddering. Food Quality and Preference, 19(7), 636-643. https://doi.org/10.1016/j.foodqual.2008.05.005.

Carrillo, E., Varela, P., Salvador, A., \& Fiszman, S. (2011). Main factors underlying consumers' food choice: a first step for the understanding of attitudes toward "Healthy Eating." Journal of Sensory Studies, 26(2), 85-95. http://dx.doi.org/10.1111/j.1745-459X.2010.00325.x.

Clarke, C., \& Best, T. (2017). Low-carbohydrate, high-fat dieters: Characteristic food choice motivations, health perceptions and behaviours. Food Quality and Preference, 62, 162-171. http://dx.doi. org/10.1016/j.foodqual.2017.07.006.

Cömert, E. D., \& Gökmen, V. (2018). Evolution of food antioxidants as a core topic of food science for a century. Food Research International, 105, 76-93. http://dx.doi.org/10.1016/j.foodres.2017.10.056. PMid:29433271.

De Jonge, J., Van Trijp, H., Goddard, E., \& Frewer, L. (2008). Consumer confidence in the safety of food in Canada and the Netherlands: the validation of a generic framework. Food Quality and Preference, 19(5), 439-451. http://dx.doi.org/10.1016/j.foodqual.2008.01.002.

Dickson-Spillmann, M., Siegrist, M., \& Keller, C. (2011). Attitudes toward chemicals are associated with preference for natural food. Food Quality and Preference, 22(1), 149-156. http://dx.doi.org/10.1016/j. foodqual.2010.09.001.

Frunzeanu, M. (2015). Using wikis, word clouds and web collaboration in Romanian primary schools. Procedia: Social and Behavioral Sciences, 180, 580-585. http://dx.doi.org/10.1016/j.sbspro.2015.02.163.

Gifford, K., \& Bernard, J. C. (2011). The effect of information on consumers' willingness to pay for natural and organic chicken. International Journal of Consumer Studies, 35(3), 282-289. http:// dx.doi.org/10.1111/j.1470-6431.2010.00929.x.

Grunert, K. G. (2005). Food quality and safety: consumer perception and demand. European Review of Agriculture Economics, 32(3), 369-391. http://dx.doi.org/10.1093/eurrag/jbi011.

Jin, Y. (2017). Development of word cloud generator software based on python. Procedia Engineering, 174, 788-792. http://dx.doi. org/10.1016/j.proeng.2017.01.223.

Kumar, Y., Yadav, D. N., Ahmad, T., \& Narsaiah, K. (2015). Recent trends in the use of natural antioxidants for meat and meat products. Comprehensive Reviews in Food Science and Food Safety, 14(6), 796812. http://dx.doi.org/10.1111/1541-4337.12156.

Lagerkvist, C. J., Amuakwa-Mensah, F., \& Tei Mensah, J. (2018). How consumer confidence in food safety practices along the food supply chain determines food handling practices: evidence from Ghana. Food Control, 93, 265-273. http://dx.doi.org/10.1016/j. foodcont.2018.06.019.

Latorres, J. M., Rancatti, A., Lasta, D., Queiroz, M., \& Mitterer-Daltoé, M. (2016). Cognitive evaluation as a food safety tool - a food handler case study. Journal of Food Safety, 36(4), 497-502. http://dx.doi. org/10.1111/jfs.12268.

Mazon, S., Menin, D., Cella, B. M., Lise, C. C., Vargas, T. O., \& Daltoé, M. L. M. (2020). Exploring consumers' knowledge and perceptions of unconventional food plants: case study of addition of Pereskia aculeata Miller to ice cream. Food Science and Technology (Campinas), 2061(1), 215-221. http://dx.doi.org/10.1590/fst.39218.

Miles, S., Brennan, M., Kuznesof, S., Ness, M., Ritson, C., \& Frewer, L. J. (2004). Public worry about specific food safety issues. British Food Journal, 106(1), 9-22. http://dx.doi.org/10.1108/00070700410515172.

Rembischevski, P., \& Caldas, E. D. (2020). Risk perception related to food. Food Science and Technology (Campinas), 2061, 1-7.

Ribeiro, J. S., Santos, M. J. M. C., Silva, L. K. R., Pereira, L. C. L., Santos, I. A., da Silva Lannes, S. C., \& da Silva, M. V. (2019). Natural antioxidants used in meat products: a brief review. Meat Science, 148, 181-188. http://dx.doi.org/10.1016/j.meatsci.2018.10.016. PMid:30389412.

Riccioli, F., Moruzzo, R., Zhang, Z., Zhao, J., Tang, Y., Tinacci, L., Boncinelli, F., De Martino, D., \& Guidi, A. (2020). Willingness to pay in main cities of Zheijiang provice (China) for quality and safety in food market. Food Control, 108, 106831. http://dx.doi.org/10.1016/j. foodcont.2019.106831.

Roininen, K., Arvola, A., \& Lähteenmäki, L. (2006). Exploring consumers perceptions of local food with two different qualitative techniques: laddering and word association. Food Quality and Preference, 17(1-2), 20-30. http://dx.doi.org/10.1016/j.foodqual.2005.04.012.

Ruby, G. E., Ungku Zainal Abidin, U. F., Lihan, S., Jambari, N. N., \& Radu, S. (2019). A cross sectional study on food safety knowledge among adult consumers. Food Control, 99, 98-105. http://dx.doi. org/10.1016/j.foodcont.2018.12.045. 
Shim, S. M., Seo, S. H., Lee, Y., Moon, G. I., Kim, M. S., \& Park, J. H. (2011). Consumers' knowledge and safety perceptions of food additives: evaluation on the effectiveness of transmitting information on preservatives. Food Control, 22(7), 1054-1060. http://dx.doi.org/10.1016/j.foodcont.2011.01.001.

Varela, P., \& Fiszman, S. M. (2013). Exploring consumers' knowledge and perceptions of hydrocolloids used as food additives and ingredients.
Food Hydrocolloids, 30(1), 477-484. http://dx.doi.org/10.1016/j. foodhyd.2012.07.001.

Wongprawmas, R., \& Canavari, M. (2017). Consumers' willingnessto-pay for food safety labels in an emerging market: the case of fresh produce in Thailand. Food Policy, 69, 25-34. http://dx.doi. org/10.1016/j.foodpol.2017.03.004. 